\title{
Cervicovaginal Safety of the Formulated, Biguanide-Based Human Immunodeficiency Virus Type 1 (HIV-1) Inhibitor NB325 in a Murine Model
}

\author{
Karissa Lozenski, ${ }^{1}$ Tina Kish-Catalone, ${ }^{2}$ Vanessa Pirrone, ${ }^{1}$ Robert F. Rando, ${ }^{3,4}$ \\ Mohamed Labib, ${ }^{3}$ Brian Wigdahl, ${ }^{1}$ and Fred C. Krebs ${ }^{1}$ \\ ${ }^{1}$ Department of Microbiology and Immunology, and Center for Molecular Therapeutics and Resistance, Center for Sexually Transmitted \\ Disease, Institute for Molecular Medicine and Infectious Disease, Drexel University College of Medicine, 245 N. 15th Street, \\ Philadelphia, PA 19102, USA \\ ${ }^{2}$ Department of Natural Sciences, DeSales University, Center Valley, PA 18034, USA \\ ${ }^{3}$ Novaflux Biosciences, Inc., Princeton, NJ 08540, USA \\ ${ }^{4}$ Medisys Health Communications, LLC, High Bridge, NJ 08829, USA
}

Correspondence should be addressed to Fred C. Krebs, fkrebs@drexelmed.edu

Received 16 May 2011; Revised 4 August 2011; Accepted 11 August 2011

Academic Editor: Anthony L. DeVico

Copyright ( $) 2011$ Karissa Lozenski et al. This is an open access article distributed under the Creative Commons Attribution License, which permits unrestricted use, distribution, and reproduction in any medium, provided the original work is properly cited.

\begin{abstract}
Vaginal microbicides that reduce or eliminate the risk of HIV-1 sexual transmission must do so safely without adversely affecting the integrity of the cervicovaginal epithelium. The present studies were performed to assess the safety of the biguanide-based antiviral compound NB325 in a formulation suitable for topical application. Experiments were performed using a mouse model of cervicovaginal microbicide application, which was previously shown to be predictive of topical agent toxicity revealed in microbicide clinical trials. Mice were exposed vaginally to unformulated NB325 or NB325 formulated in the hydroxyethyl cellulose "universal placebo." Following exposures to formulated 1\% NB325 for $10 \mathrm{~min}$ to $24 \mathrm{~h}$, the vaginal and cervical epithelia were generally intact, although some areas of minimal vaginal epithelial damage were noted. Although formulated NB325 appeared generally safe for application in these studies, the low but observable level of toxicity suggests the need for improvements in the compound and/or formulation.
\end{abstract}

\section{Introduction}

Despite efforts to combat human immunodeficiency virus type 1 (HIV-1) infection through the use of highly effective combination therapies, HIV-1 has continued to spread. By 2009, the number of individuals living with HIV-1 reached a staggering 33.3 million people worldwide [1]. Since the beginning of the epidemic almost 30 years ago, the proportion of HIV-1-infected women in this population has risen steadily, stabilizing recently at approximately $52 \%$. Women in sub-Saharan Africa are at particular risk, as evidenced by the greater prevalence of women (approximately 60\%) in the HIV-1-infected population and the predominant transmission of HIV-1 through unprotected heterosexual intercourse [1]. This route of transmission continues to prevail because effective methods of prevention, such as the male condom, are inconsistently used due to various social, cultural, economic, and religious issues.

To address the critical need for an effective and acceptable means to check the spread of HIV-1, numerous investigators around the world are working toward the development of microbicides, which are formulated chemical entities that can be applied vaginally or rectally to prevent or eliminate HIV-1 transmission [2-5]. The ideal microbicide would be highly active against HIV-1 but may also have activity against other sexually transmitted disease pathogens. For optimal acceptability, a formulated microbicide should be colorless, tasteless, and odorless to allow for discretion in 
its use and should also be inexpensive and easy to apply [3, 6]. Importantly, a topical formulation containing an active pharmaceutical ingredient (API) must be safe for topical vaginal and/or rectal use, causing no adverse changes in epithelial barrier functions and no local inflammation that might increase susceptibility to HIV-1 infection. Although a microbicide is not yet available for worldwide use, the reverse transcriptase inhibitor tenofovir was recently shown to be a safe, effective microbicide API in women at risk for HIV-1 infection [7].

Our efforts have been directed toward the development of biguanide-based compounds for use in microbicides effective against HIV-1. Polybiguanides (PBGs) are polycationic in nature and are made up of repeating biguanide units that are separated by hydrocarbon linkers of varying lengths [8]. PBGs have been used safely for more than 30 years for vaginal disinfection (chlorhexidine digluconate), antimalarial therapy (proguanil), and treatment of type 2 diabetes (metformin). They are also used as the active ingredient in contact lens disinfectants, mouth rinses, and wound disinfectants [8-16].

Our studies of PBG compounds as microbicide APIs have encompassed activity, safety, and mechanism of action. Early experiments with a small number of PBGs indicated that polyethylene hexamethylene biguanide (PEHMB) was an effective HIV-1 inhibitor characterized by minimal in vitro cytotoxicity [8]. Expanded studies of structure-activity relationships among different PBG compounds demonstrated clear relationships between molecule structure and biological activity [17]. Furthermore, the results of these studies suggested that PEHMB acted against X4 and R5 strains of HIV-1 as a viral entry inhibitor by interacting with the host cell rather than the virus [17]. In a series of experiments focused on confirming this mechanism of action against HIV-1, PEHMB (later designated NB325) was shown to inhibit HIV-1 infection by interacting specifically with the second extracellular loop of CXCR4, which serves as the HIV-1 coreceptor [18]. Additional investigations demonstrated that this interaction and the inhibitory effect on HIV-1 infection were persistent, providing protection from infection even after removal of the compound from the culture medium [19].

The low in vitro cytotoxicity of PEHMB (NB325) suggested that this compound would also be characterized as safe in a Swiss Webster mouse model used to assess cervicovaginal toxicity associated with compound exposure. Previous studies using this murine model of microbicide toxicity (i) confirmed the cervicovaginal toxicity and inflammation associated with topical application of nonoxynol-9 (N-9) in women [20] and (ii) corroborated differences in acceptability between two different formulations of the microbicide API C31G [21]. In previous mouse model experiments relevant to the present studies, in vivo exposure to unformulated $1 \%$ PEHMB resulted in minimal epithelial damage and negligible local inflammation relative to N-9 and control mice [20]. These results were consistent with those from in vitro studies of compound cytotoxicity, which demonstrated that PEHMB was more than 350-fold less cytotoxic than N-9 $[8,20]$.
The objectives of the present study were to assess the safety of NB325 formulated at two concentrations $(0.5 \%$ and $1 \%)$ and to investigate time-dependent effects of application on cervicovaginal integrity. Experiments were focused on the acute time points of $10 \mathrm{~min}, 2 \mathrm{~h}$, and $4 \mathrm{~h}$ postapplication, because these exposure durations were previously shown to provide important information for gauging acute epithelial toxicity following N-9 or C31G exposure [20-23]. The extended time points of $8 \mathrm{~h}$ and $24 \mathrm{~h}$ were also included to provide a full range of observations over a $24 \mathrm{~h}$ period. Histological analyses of exposed tissues indicated little to no toxicity after exposure to $0.5 \% \mathrm{NB} 325$ and minimal toxicity after exposure to $1 \%$ NB325 for both unformulated and formulated compound. Interestingly, changes in epithelial integrity that were observed following exposure to NB325 were noted in the vagina rather than in the cervix, where N-9 toxicity was readily apparent in previous studies [20]. These studies provide further evidence of the topical safety of biguanide-based compounds as microbicide APIs.

\section{Materials and Methods}

2.1. Unformulated and Formulated NB325. NB325 was synthesized as previously described for polyhexamethylene biguanide and PEHMB $[8,18,24]$. The molecular mass of NB325 ranged from 900 to $1,900 \mathrm{Da}$ with a median molecular mass of approximately 1,400 Da. NB325 was determined to be soluble in water and to exhibit polydispersity. Gel formulation of NB325 was performed by the International Partnership for Microbicides using a hydroxyethyl cellulose (HEC) based gel, otherwise known as the "universal placebo" [25].

\subsection{Assessing the In Vivo Effect of Cervicovaginal NB325 Ex-} posure in a Murine Model. These experiments, which were similar to previously performed studies [20,21, 23], used 5- to 6-week-old female outbred Swiss Webster mice (CFW) (Charles River Laboratories, Wilmington, Mass). Prior to compound or formulation application, the mice were synchronized using a $0.2 \mathrm{~mL}$ subcutaneous injection of DepoProvera (Pharmacia and Upjohn Company, Bridgewater, NJ) at 7 and 3 days before the start of each experiment. The Depo-Provera was diluted in Ringer's lactated saline solution (Baxter, Deerfield, Ill) to allow administration of $3 \mathrm{mg} / \mathrm{animal}$. Mice were anesthetized with a formulation of ketamine/xylazine $(100-200 \mathrm{mg} / \mathrm{kg}$ and $5-10 \mathrm{ng} / \mathrm{kg}$, respectively) before the intravaginal application of NB325. Anesthetized animals received an intravaginal inoculation $(60 \mu \mathrm{L})$ of NB325. Mice treated with saline alone or $1 \% \mathrm{~N}$ 9 (diluted in saline) were included as controls to evaluate the morphology of normal or damaged cervicovaginal mucosal tissue, respectively. After treatment, mice were sacrificed humanely, and the cervicovaginal tracts were surgically excised and prepared for histological examination. Each experiment evaluated 3 animals per time point within each experimental group.

Mice were sacrificed after exposure for $10 \mathrm{~min}, 2 \mathrm{~h}$, or $4 \mathrm{~h}$ and after longer exposures for $8 \mathrm{~h}$ or $24 \mathrm{~h}$. The durations 


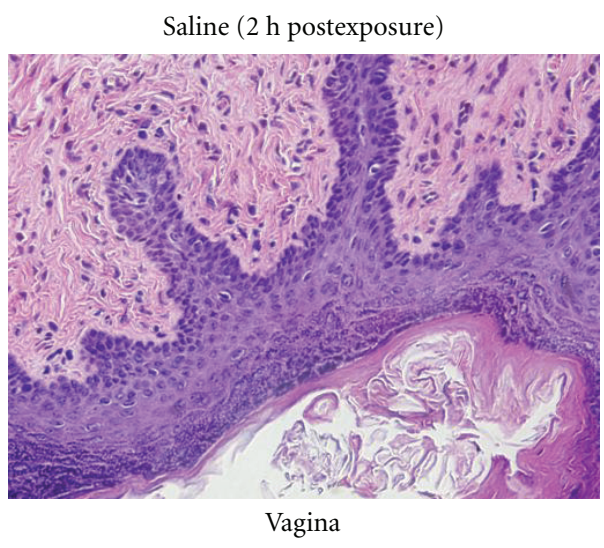

(a)

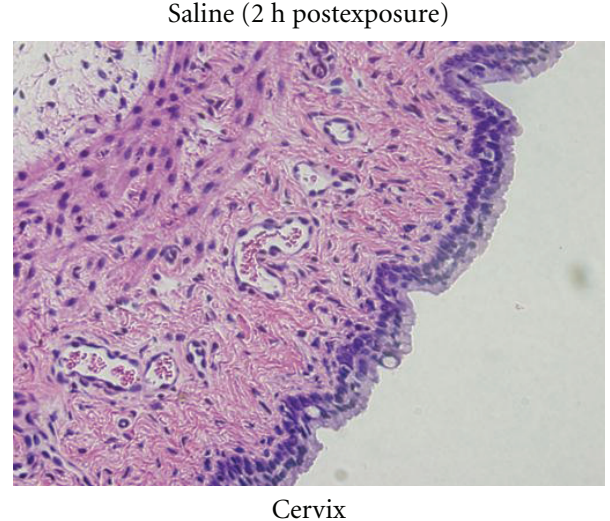

(b)

Figure 1: Exposure to saline results in no damage to the cervicovaginal epithelia. Mice were exposed to saline and sacrificed at $10 \mathrm{~min}, 2 \mathrm{~h}$, $4 \mathrm{~h}$, or $8 \mathrm{~h}$ after application. H\&E-stained vaginal (a) and cervical (b) epithelial tissues were analyzed for damage. Representative micrograph fields from the $2 \mathrm{~h}$ exposure are shown. Images are representative of three mice per exposure duration.

of acute exposure were established previously to characterize the appearance of epithelial damage following a single microbicide application [20]. The longer time points were shown to be useful for characterizing the time course of epithelial repair and resolution of tissue inflammation.

All excised cervicovaginal tissues were formalin-fixed and embedded in paraffin using previously described procedures $[20,21,23]$. Paraffin-embedded samples were stained with hematoxylin and eosin (H\&E) for gross morphological analyses, and representative fields from each treatment group were documented in photomicrographs. Tissue toxicity was assessed observationally across multiple sections.

\section{Results}

\subsection{In Vivo Exposure to Unformulated NB325 Causes Minor} Changes in Cervicovaginal Epithelial Integrity. Although clinical studies of microbicide safety have included assessments of female reproductive tract health and integrity following application, these studies were often conducted at postexposure durations in excess of $24 \mathrm{~h}$. As a result, information regarding the acute effects of microbicide exposure has been lacking. Our in vivo studies of N-9 using a mouse model of cervicovaginal toxicity [20] indicated the need to include acute and extended exposures in these experiments in order to observe both short- and long-term effects of topical application. These results guided the present studies of NB325 safety.

As controls in these experiments, mice were exposed to either saline or unformulated $\mathrm{N}-9(1 \%)$ to provide illustrations of normal or damaged cervicovaginal epithelial tissues, respectively. Saline exposure for $2 \mathrm{~h}$ caused no damage to either the vaginal or the cervical epithelial tissue (Figure 1); identical results were obtained after exposures of $10 \mathrm{~min}$, $4 \mathrm{~h}, 8 \mathrm{~h}$, or $24 \mathrm{~h}$ (data not shown). As in previous studies [20], N-9 exposure resulted in severe cervical epithelial shedding and breaks in the epithelia that were greatest at $2 \mathrm{~h}$ postexposure (Figure 2(b)) and were still evident at $4 \mathrm{~h}$ and $8 \mathrm{~h}$ after N-9 application (Figures 2(d), 2(f)). N-9-associated cervical damage was resolved by $24 \mathrm{~h}$ postexposure, as these tissues were similar in appearance to tissues from salineexposed mice (data not shown). The vaginal epithelium was unaffected by N-9 exposure (Figures 2(a), 2(c), 2(e)).

Initial NB325 mouse model studies involved the vaginal application of unformulated NB325 at concentrations of $0.5 \%$ or $1 \%$. At its lower concentration $(0.5 \%)$, unformulated NB325 caused little or no postexposure cervicovaginal epithelial damage (data not shown). Although epithelial cell sloughing and breaks in the epithelium were observed sporadically in the vagina and cervix, respectively, these minor indications of toxicity were not apparent by $24 \mathrm{~h}$ postexposure (data not shown).

Exposure to $1 \%$ unformulated NB325 resulted in a slightly greater level of toxicity compared to $0.5 \%$ NB325. At 10 min postapplication, NB325 exposure resulted in no damage to the cervicovaginal tract (Figures 3(a), 3(b)). In the vagina and cervix, the tissue appeared the same as the placebo control, the vaginal epithelium retained the keratin layer, the cervix had no cells shed into the lumen, and mucus production was suggested by the observation that mucusproducing cells were present in the epithelial layer. By $2 \mathrm{~h}$ and $4 \mathrm{~h}$ postapplication, the cervix was still unaffected (Figures 3(d), 3(f)), whereas some toxicity was apparent in the vaginal epithelium (Figures 3(c), 3(e)). At $2 \mathrm{~h}$ after application, the vagina began showing signs of toxicity in the form of cells appearing to loosen from the upper layers of the stratified squamous tissue and thinning of the epithelial layer. By $4 \mathrm{~h}$ after application, cells were actively shed from the vaginal epithelium and were present in the lumen. At the extended exposure durations of $8 \mathrm{~h}$ and $24 \mathrm{~h}$, little to no toxicity was observed in the vagina (Figures 4(a), 4(c)), although at $24 \mathrm{~h}$ some shed tissue was still apparent in the lumen. At $8 \mathrm{~h}$ postexposure, the cervical epithelium was generally intact, with evidence of a small number of cells present in the lumen (Figure 4(b)). By $24 \mathrm{~h}$ postexposure, however, these luminal 


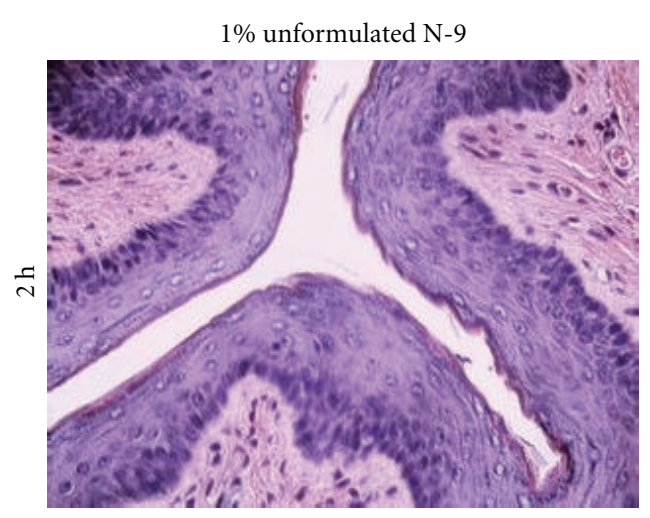

(a)

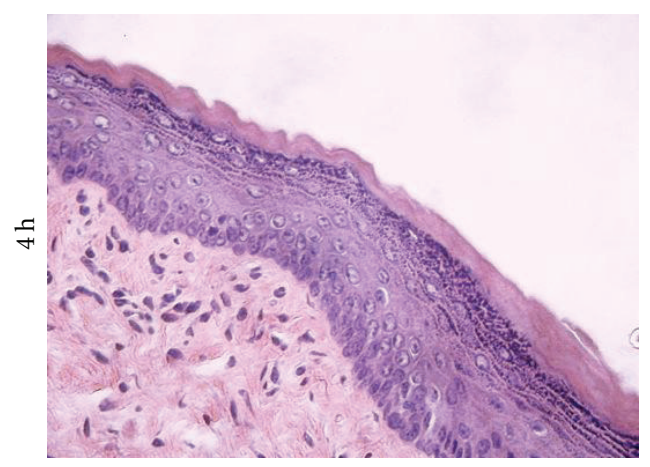

(c)

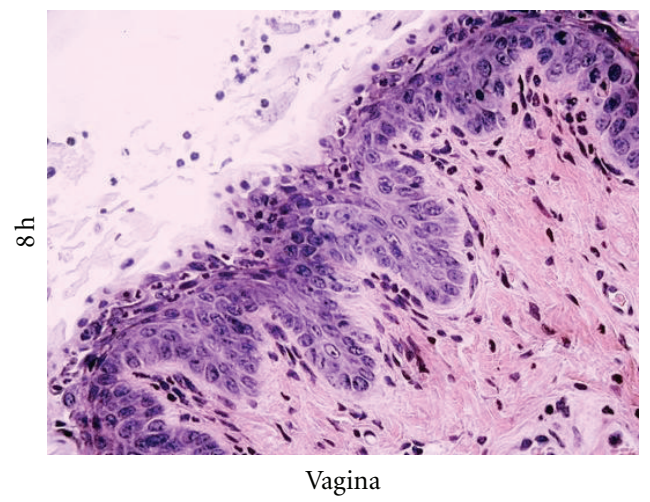

(e)

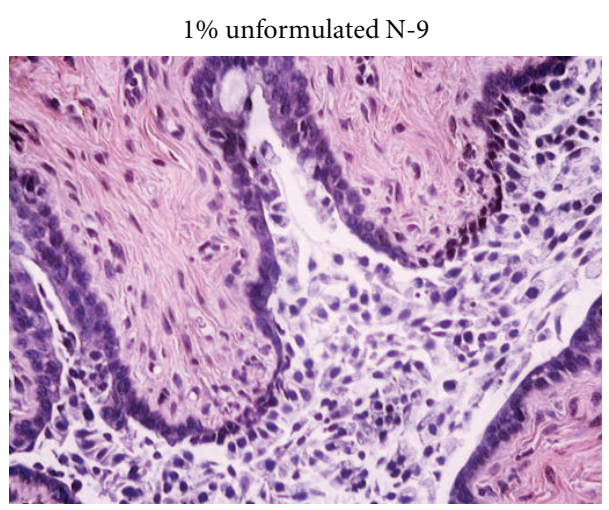

(b)

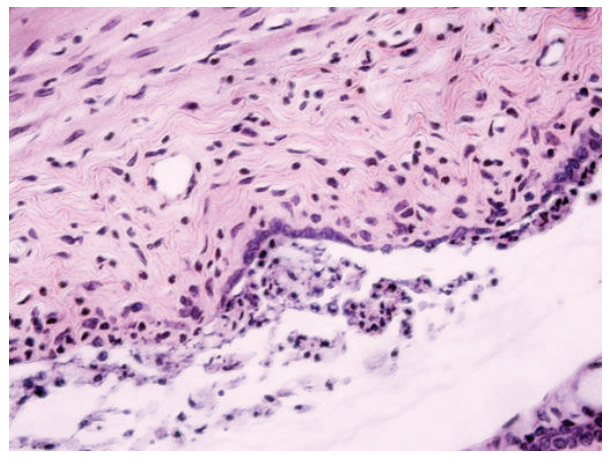

(d)

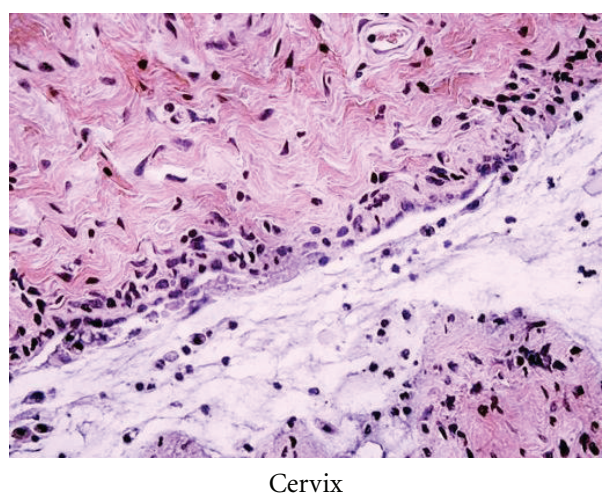

(f)

Figure 2: Exposure to N-9 results in severe damage to cervical epithelial tissues. Mice were exposed to N-9 and sacrificed at 10 min, $2 \mathrm{~h}$, $4 \mathrm{~h}, 8 \mathrm{~h}$, or $24 \mathrm{~h}$ after application. H\&E-stained vaginal ((a), (c), (e)) and cervical ((b), (d), (f)) epithelial tissues were analyzed for damage. Representative micrograph fields from the $2 \mathrm{~h}, 4 \mathrm{~h}$, and $8 \mathrm{~h}$ exposures are shown. Images are representative of three mice per exposure duration. Tissues exposed to N-9 for $10 \mathrm{~min}$ and $24 \mathrm{~h}$ were similar to saline-exposed tissues (data not shown).

cells were no longer present, and the tissue appeared normal (Figure 4(d)).

3.2. NB325 Formulation Does Not Impact Its Effect on Cervicovaginal Epithelial Integrity. To explore the potential cervicovaginal safety of the formulated compound, NB325 was incorporated into a HEC-based gel, otherwise known as the universal placebo [25], at final concentrations of $0.5 \%$ and $1 \%$. Vaginal and cervical epithelial tissues from mice exposed to the gel without NB325 (placebo) were indistinguishable from saline-exposed tissues; there was no observable epithelial damage at any time point (Figure 5 and data not shown).

The effects of exposure to NB325 formulated at 0.5\% were similar to those observed after exposure to unformulated NB325 at the same concentration (data not shown). In the vagina, indications of minor toxicity were observed at $8 \mathrm{~h}$ postexposure in the form of epithelial layer thinning, indicating that shedding may have occurred at some point between the $4 \mathrm{~h}$ and $8 \mathrm{~h}$ time points. By $24 \mathrm{~h}$ postexposure, 


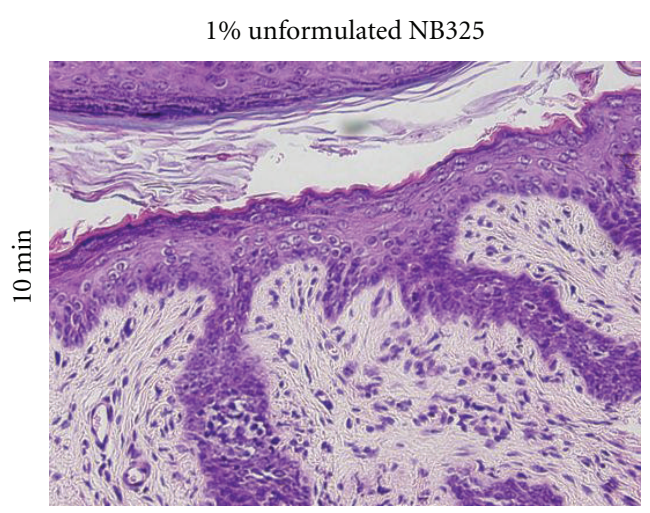

(a)

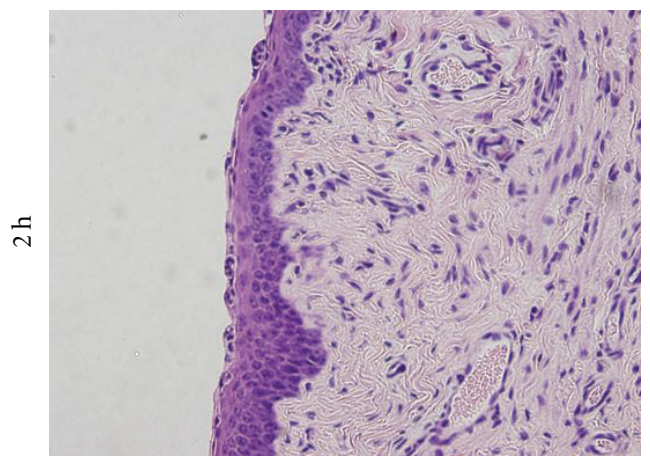

(c)

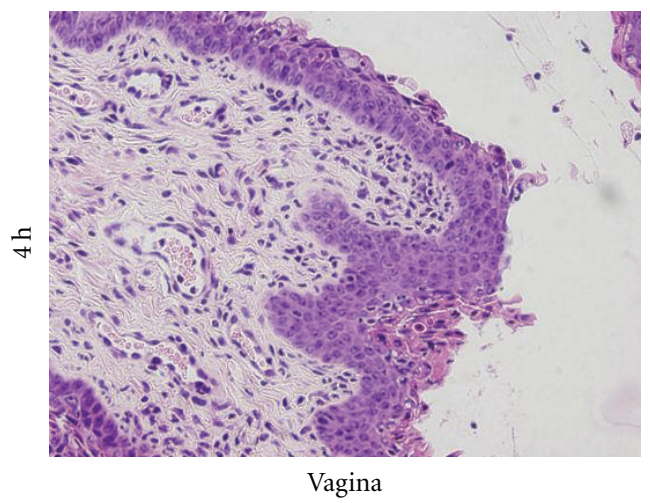

(e)
$1 \%$ unformulated NB325

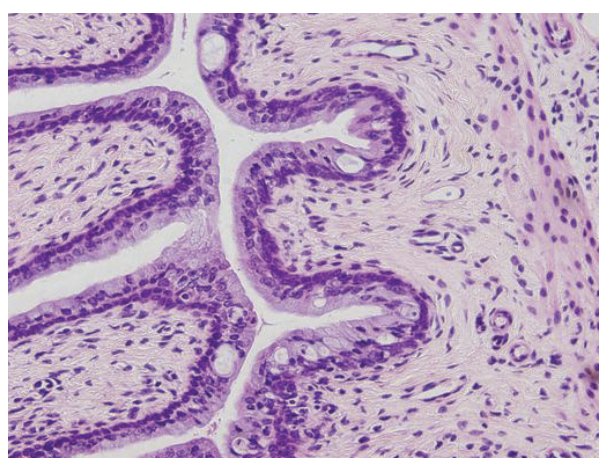

(b)

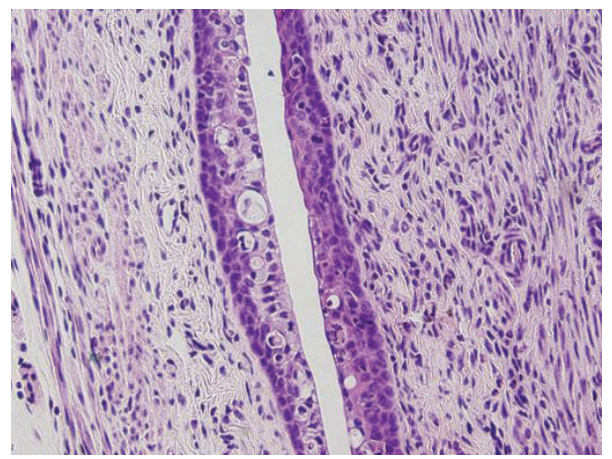

(d)

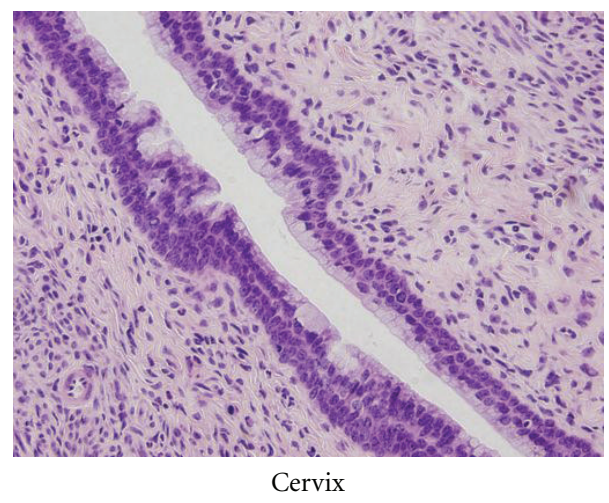

(f)

Figure 3: Short exposures to 1\% unformulated NB325 result in isolated damage to the vaginal epithelium. Mice were exposed to $1 \%$ unformulated NB325 for $10 \mathrm{~min}, 2 \mathrm{~h}$, or $4 \mathrm{~h}$ prior to sacrifice and cervicovaginal tissue isolation. H\&E-stained vaginal ((a), (c), (e)) and cervical ((b), (d), (f)) tissue sections were analyzed for epithelial damage. Representative micrograph fields for each exposure are shown. Images are representative of three mice per exposure duration.

epithelial damage was no longer apparent; tissues were similar in appearance to the controls. The cervix appeared to be unaffected by any length of exposure to $0.5 \%$ formulated NB325.

Similar experiments were performed to examine the effects of a formulation containing a higher concentration (1\%) of NB325. At $10 \mathrm{~min}$ following application, minimal damage to the vagina was observed (Figure 6(a)), whereas the cervix appeared normal and showed indications of mucus production (Figure 6(b)). By $2 \mathrm{~h}$ after application, signs of toxicity in the vaginal tract were apparent, indicated by the presence of sloughed cells in the lumen and thinning of the epithelial layer (Figure 6(c)). At $4 \mathrm{~h}$ after application, an increase in vaginal tissue damage relative to the 2$\mathrm{h}$ exposure was observed (Figure 6(e)). By $8 \mathrm{~h}$ and $24 \mathrm{~h}$ postexposure, however, vaginal epithelia appeared normal, with no observable residual tissue damage (Figures 7(a), $7(\mathrm{c})$ ). Although cervical epithelial tissues exposed to formulated 1\% NB325 were generally intact, some cell infiltration beneath the basal layer of the cervical epithelium was visible 


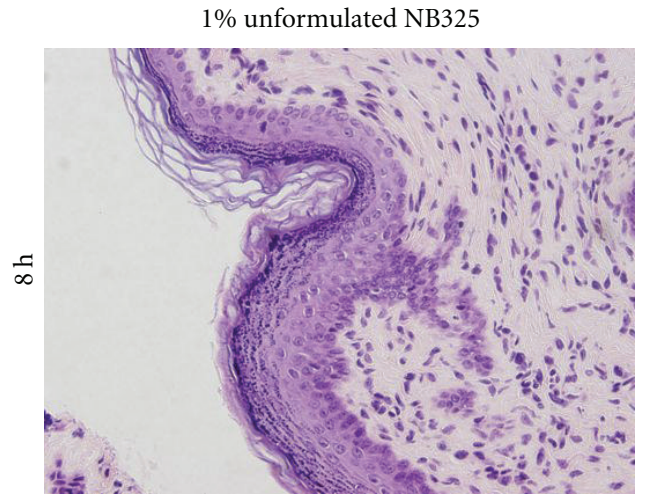

(a)

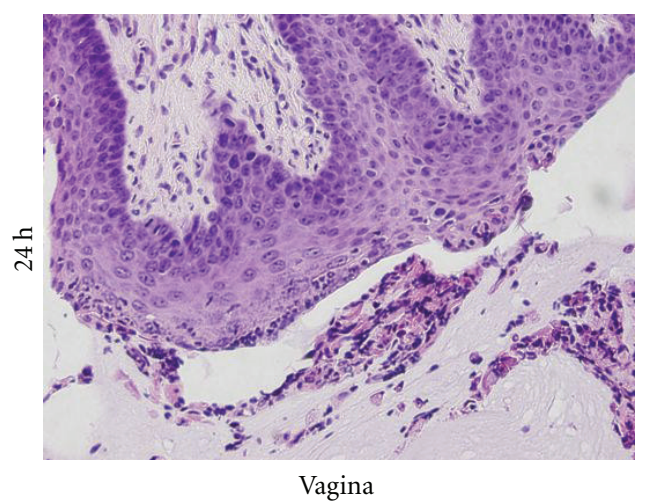

(c)

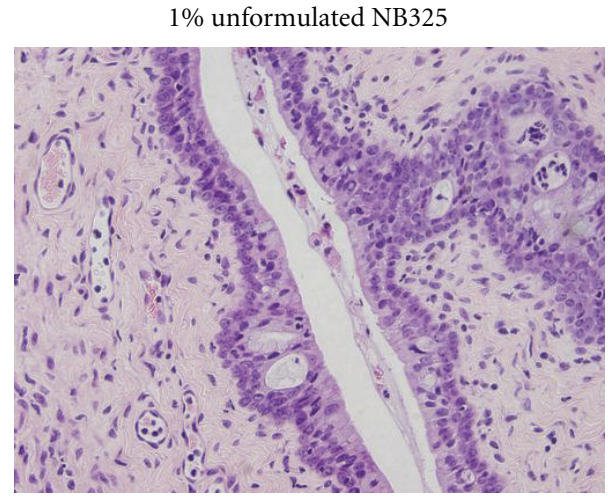

(b)

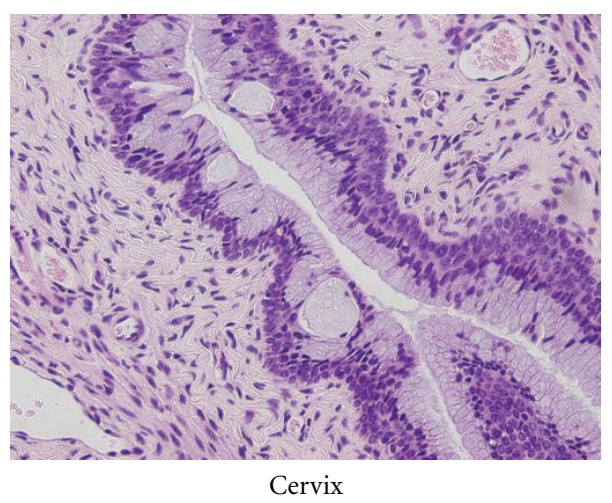

(d)

FIgURE 4: Exposure to $1 \%$ unformulated NB325 for $8 \mathrm{~h}$ or $24 \mathrm{~h}$ is characterized by little or no change in cervicovaginal epithelial integrity. Mice were exposed to $1 \%$ unformulated NB325 for $8 \mathrm{~h}$ or $24 \mathrm{~h}$ prior to sacrifice and cervicovaginal tissue isolation. H\&E-stained tissue sections were analyzed for damage to the vaginal ((a), (c)) and cervical ((b), (d)) epithelia. Representative micrograph fields for each exposure are shown. Images are representative of three mice per exposure duration.

Placebo gel ( $2 \mathrm{~h}$ postexposure)

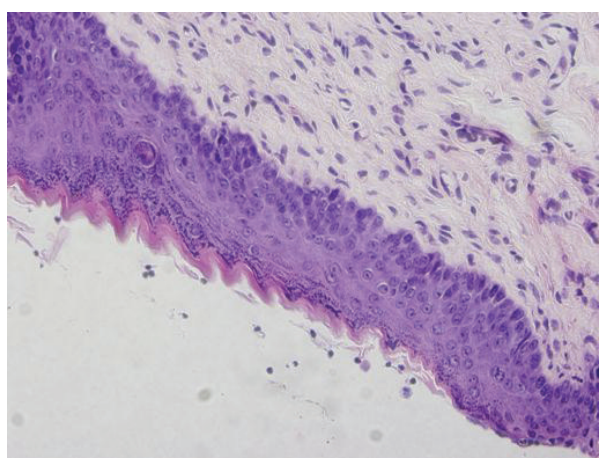

Vagina

(a)

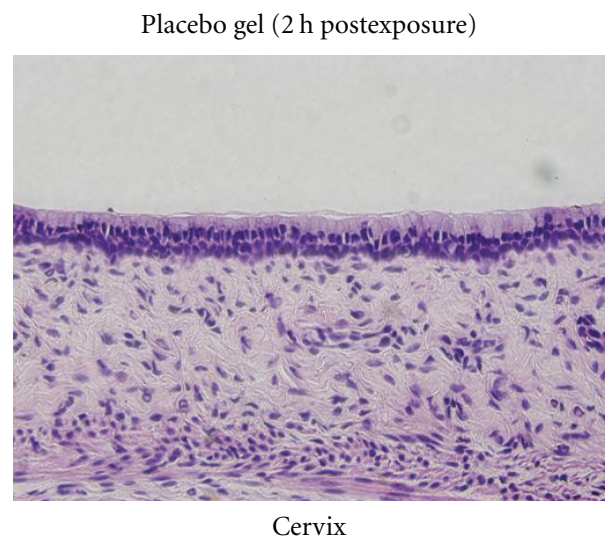

(b)

FIgURE 5: Application of gel only (placebo) causes no damage to the cervicovaginal epithelium. Mice were exposed to the HEC-based formulation placebo and sacrificed after application for $10 \mathrm{~min}, 2 \mathrm{~h}, 4 \mathrm{~h}$, or $8 \mathrm{~h}$. Vaginal (a) and cervical epithelial tissues (b) were subsequently isolated and analyzed for damage. Representative micrograph fields from the $2 \mathrm{~h}$ exposure are shown. Images are representative of three mice per exposure duration. 


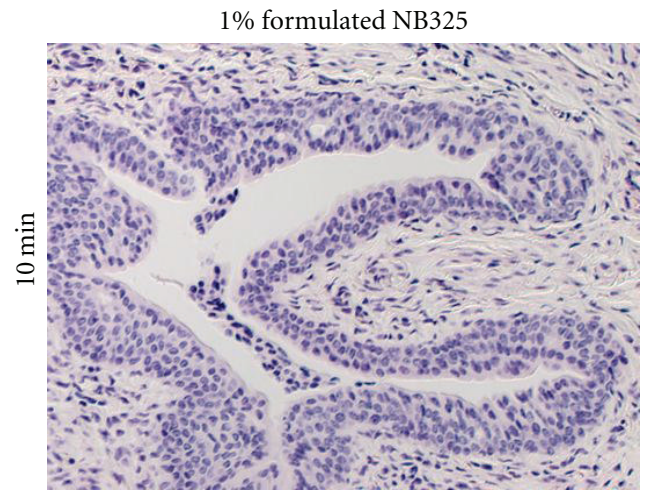

(a)

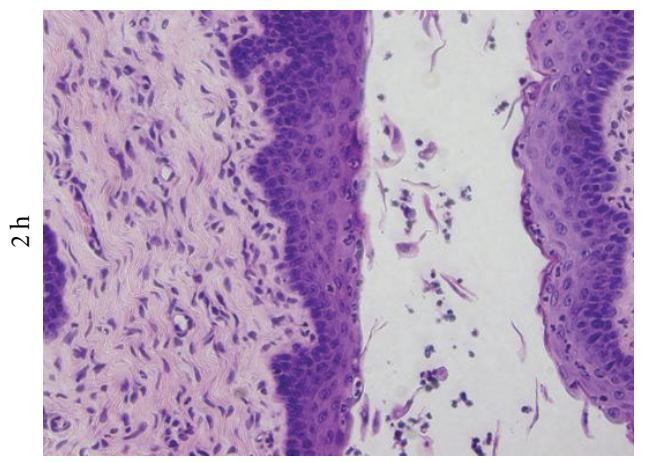

(c)

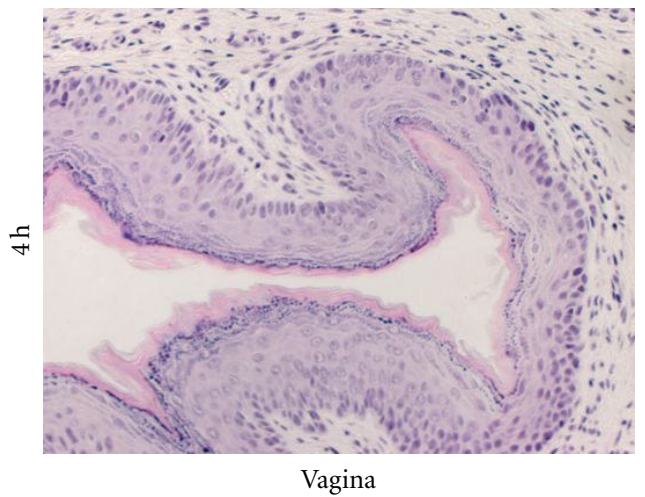

(e)

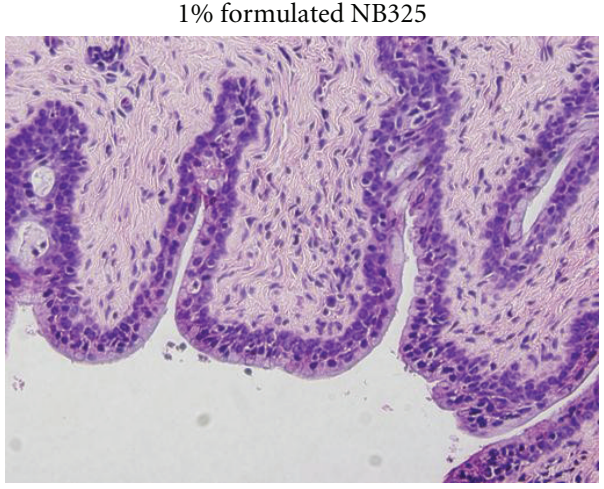

(b)

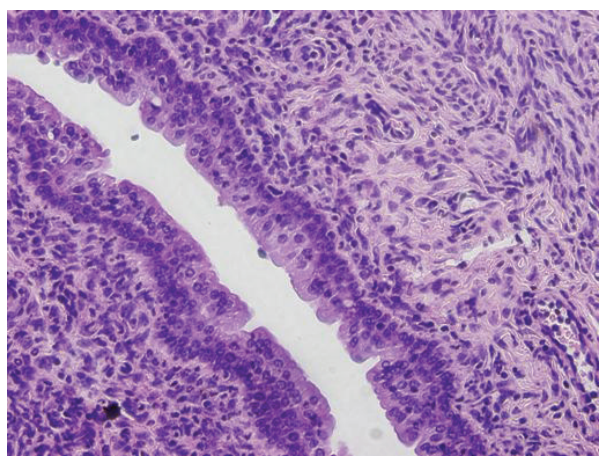

(d)

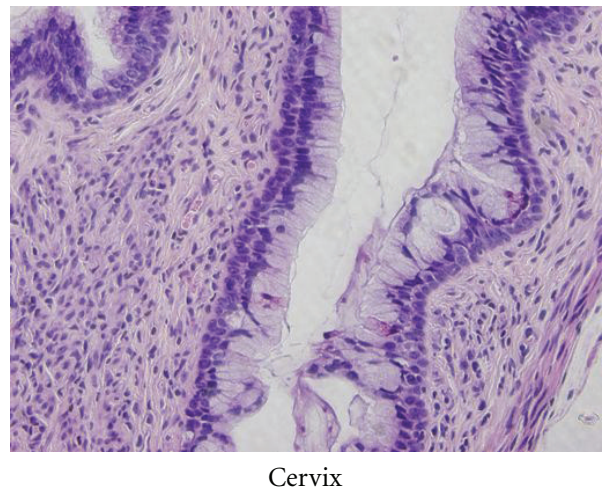

(f)

Figure 6: Short exposures to NB325 formulated at 1\% result in mild vaginal epithelial toxicity. Mice were exposed to $1 \%$ formulated NB325 for $10 \mathrm{~min}, 2 \mathrm{~h}$, or $4 \mathrm{~h}$ prior to sacrifice and isolation of reproductive tract tissues. H\&E-stained tissue sections were analyzed for toxicity to the vaginal ((a), (c), (e)) and cervical ((b), (d), (f)) epithelia. Representative micrograph fields for each exposure are shown. Images are representative of three mice per exposure duration.

at $2 \mathrm{~h}$ and $4 \mathrm{~h}$ postexposure (Figures $6(\mathrm{~d}), 6(\mathrm{f}))$. Interestingly, the sporadic appearance of mild cervical epithelial damage was noted at $8 \mathrm{~h}$ after application (Figure 7(b)). This damage was characterized by a "loose" appearance of cells along the epithelial layer, suggesting the presence of epithelial cells in the process of shedding. At $24 \mathrm{~h}$, however, the cervix appeared normal and intact (Figure $7(\mathrm{~d})$ ).

\section{Discussion}

The vaginal and cervical epithelia within the female reproductive tract provide physical barriers that impede pathogen access and play host to cells that mount immunologic responses to those pathogens. The integrity of this physical and immunologic barrier is crucial to maintaining the health 


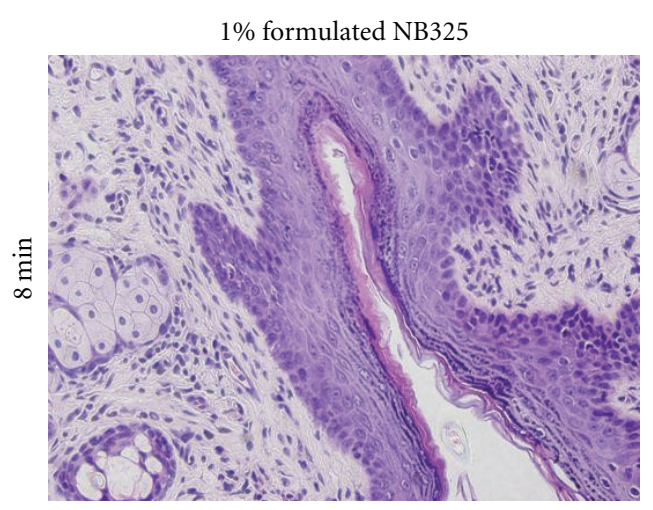

(a)

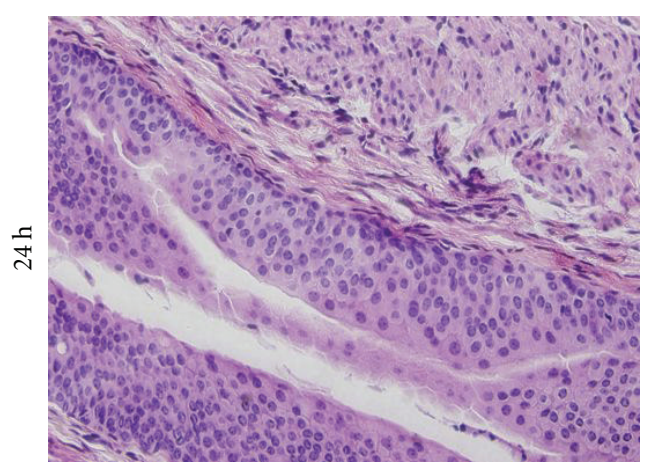

Vagina

(c)

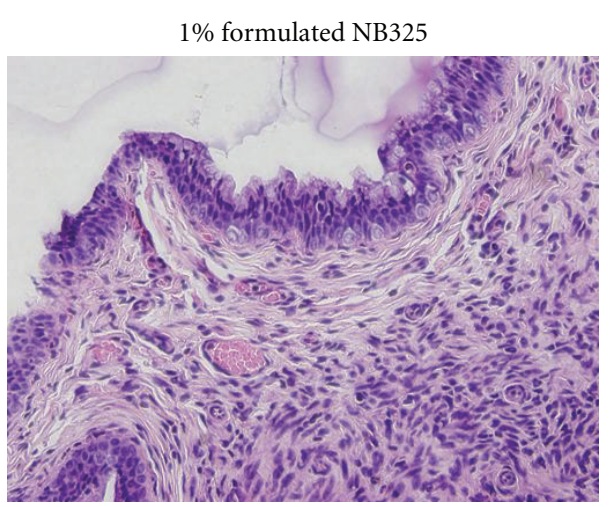

(b)

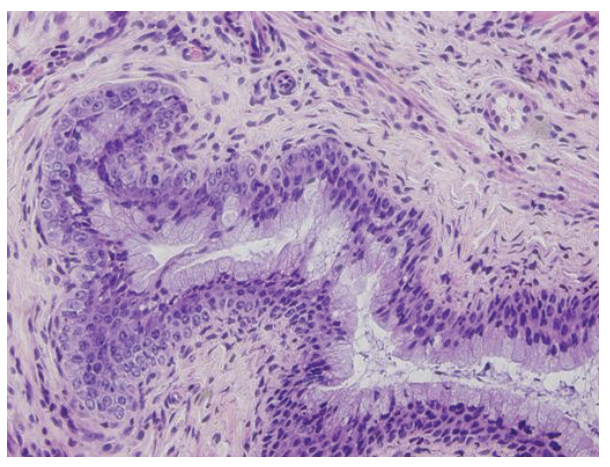

Cervix

(d)

Figure 7: Cervicovaginal epithelial integrity after exposure to $1 \%$ formulated NB325 for $8 \mathrm{~h}$ or $24 \mathrm{~h}$ is similar to that of controls. Mice were exposed to $1 \%$ formulated NB325 for $8 \mathrm{~h}$ or $24 \mathrm{~h}$ prior to sacrifice and isolation of reproductive tract tissues. H\&E-stained tissue sections were analyzed for toxicity to the vaginal ((a), (c)) and cervical ((b), (d)) epithelia. Representative micrograph fields for each exposure are shown. Images are representative of three mice per exposure duration.

of the cervicovaginal environment; disruption of this barrier could result in an increased risk of infection by sexually transmitted disease pathogens. With regard to HIV-1, breaks in these natural barriers can provide a direct route that the virus can take to reach susceptible cells and establish infection. Thus, assessment of cervicovaginal epithelial integrity following exposure to a candidate microbicide is an important part of demonstrating the safety of a topical vaginal formulation and its API. However, a complete evaluation of in vivo safety must also encompass other approaches, such as investigations of inflammatory cell infiltration [20,21], assays of cytokine expression and release, and experiments to demonstrate increased susceptibility to infection following topical microbicide exposure [26].

The present mouse model studies, which were performed to provide an initial evaluation of formulated NB325 safety, offer the basis for several conclusions. First, the results of experiments involving unformulated NB325 suggest a much greater level of safety relative to $\mathrm{N}-9$, which has been shown in these and other studies to cause severe damage to cervicovaginal epithelial tissues. These studies corroborate and expand on previous results that demonstrated the minimal effect of unformulated PEHMB on epithelial integrity and the absence of CD45-positive immune cell infiltration following exposure [20]. The present studies indicate a similar level of safety for unformulated NB325, which was produced through the application of refinements to the synthetic methods used to produce PEHMB $[17,18]$.

Second, these results also indicate a relative level of in vivo safety for NB325 formulated in an HEC-based gel. The effects of formulated NB325 on vaginal epithelial integrity are in sharp contrast to the severe and widespread cervical epithelial damage and tissue sloughing (as well as induction of immune cell infiltration) caused by the application of unformulated and formulated N-9 (Conceptrol) [20]. In fact, the results of mouse experiments involving formulated NB325 are comparable to the results of similar experiments using $1 \%$ formulated C31G [21], which was shown in several independent clinical trials (as the topical agent SAVVY) to be safe and acceptable for human application [27-29]. However, because the $1 \%$ formulated NB325 appeared to be slightly more toxic in vivo relative to the formulation containing $0.5 \% \mathrm{NB} 325$, the concentration of NB325 in future microbicide formulations will need to be considered further.

The indication of concentration-dependent effects on epithelial integrity also hints at the bioavailability of NB325 in the HEC-based formulation. Although NB325 
bioavail-ability was not addressed in the present studies, preliminary experiments involving HIV-1 infection of indicator cells in the presence of formulated NB325 indeed demonstrated antiviral activity attributable to NB325 (data not shown). However, the antiviral activity of NB325 in this transwell-based experimental system was partly obscured by the barrier effect of the viscous HEC-based gel, indicating a limitation of this method for measuring drug availability and biological activity and the need for additional investigations in this direction.

The third conclusion concerns the location of the relatively limited epithelial damage caused by unformulated and formulated NB325. When epithelial damage was observed as a consequence of NB325 exposure, it was found predominantly in the vagina and observed infrequently in the cervix. In contrast, previous investigations demonstrated that the severe epithelial damage caused by N-9 was confined to the cervix; the vaginal epithelium appeared to be resistant to any damage caused by a single application of N-9 $[17,20]$. Similarly, losses in epithelial integrity associated with C31G exposure were found exclusively in the cervix [21].

These differences may be related both to the chemical nature of each compound and the respective microenvironments of the vagina and cervix. NB325 is an aqueous, nonsurfactant compound with a net positive charge at physiological $\mathrm{pH}$, whereas N-9 and C31G are both surfactants. Within the cervix, mucus released from the epithelial surface may interact with NB325 and protect the columnar epithelial cells from any toxicity associated with NB325. This layer of cervical mucus may not afford the same protection against surfactants such as N-9 or C31G. Conversely, the absence of mucus in the vagina may leave the vaginal epithelium vulnerable to the potential effects of NB325. However, the structure of the stratified squamous epithelium in the vagina may be more impervious to the surfactant properties of $\mathrm{N}$ 9 or C31G. The present studies and results (i) stress the importance of considering cervicovaginal environmental factors in designing and evaluating candidate microbicides and (ii) highlight the potential impact of API and formulation chemistry on microbicide safety.

Compound chemistry may also be highly relevant to topical vaginal microbicide clinical efficacy. Microbicides shown to be safe but ineffective in clinical trials (Ushercell, Carraguard, and PRO2000) may have failed due to electrostatic interactions between their polyanionic APIs and charged seminal plasma components that interfere with their antiviral activities $[30,31]$. Because NB325 is polycationic, its antiviral activity should be unaltered in the presence of semen. Indeed, cationic peptides endogenous to semen have been shown to provide an inherent antiviral activity against HIV-1 [32]. The effects of both male and female reproductive tract secretions on NB325 activity will be addressed as part of the preclinical development of this compound.

\section{Conclusions}

In vivo experiments involving a mouse model of cervicovaginal toxicity provide support for the safe use of a gel formu- lation containing the biguanide-based antiviral compound NB325 as a topical vaginal microbicide. However, indications of minor dose-dependent effects on epithelial integrity and regional differences in the effects of NB325 on the cervicovaginal tract indicate the need for further preclinical studies to arrive at an optimal API concentration and formulation.

\section{Acknowledgments}

Grant from the National Institute of Allergy and Infectious Diseases, National Institutes of Health (1 U19 AI076965; M. Labib, Principal Investigator and B. Wigdahl, Coprincipal Investigator). Dr. F. C. Krebs was also supported by faculty development funds provided by the Department of Microbiology and Immunology, Drexel University College of Medicine and the Institute for Molecular Medicine and Infectious Disease.

\section{References}

[1] Joint United Nations Programme on HIV/AIDS (UNAIDS), "Global report: UNAIDS report on the global AIDS epidemic 2010," 2010, http://www.unaids.org/globalreport/Global_report.htm .

[2] J. Balzarini and L. Van Damme, "Microbicide drug candidates to prevent HIV infection,” Lancet, vol. 369, no. 9563, pp. 787797, 2007.

[3] G. Ramjee, "Microbicide research: current and future directions," Current Opinion in HIV and AIDS, vol. 5, no. 4, pp. 316-321, 2010.

[4] J. Nuttall, "Microbicides in the prevention of HIV infection: current status and future directions," Drugs, vol. 70, no. 10, pp. 1231-1243, 2010.

[5] T. M. Zydowsky, "Microbicides: chemistry, structure, and strategy," Current Opinion in HIV and AIDS, vol. 3, no. 5, pp. 548-553, 2008.

[6] G. Ramjee, A. Kamali, and S. McCormack, "The last decade of microbicide clinical trials in Africa: from hypothesis to facts," AIDS, vol. 24, no. 4, pp. S40-S49, 2010.

[7] Q. A. Karim, S. S. A. Karim, J. A. Frohlich et al., "Effectiveness and safety of tenofovir gel, an antiretroviral microbicide, for the prevention of HIV infection in women," Science, vol. 329, no. 5996, pp. 1168-1174, 2010.

[8] F. C. Krebs, S. R. Miller, M. L. Ferguson, M. Labib, R. F. Rando, and B. Wigdahl, "Polybiguanides, particularly polyethylene hexamethylene biguanide, have activity against human immunodeficiency virus type 1," Biomedicine and Pharmacotherapy, vol. 59, no. 8, pp. 438-445, 2005.

[9] M. Shubair, R. Stanek, S. White, and B. Larsen, "Effects of chlorhexidine gluconate douche on normal vaginal flora," Gynecologic and Obstetric Investigation, vol. 34, no. 4, pp. 229233, 1992.

[10] B. Stray-Pedersen, T. Bergan, A. Hafstad, E. Normann, J. Grøgaard, and M. Vangdal, "Vaginal disinfection with chlorhexidine during childbirth," International Journal of Antimicrobial Agents, vol. 12, no. 3, pp. 245-251, 1999.

[11] D. Overbosch, H. Schilthuis, U. Bienzle et al., "Atovaquoneproguanil versus mefloquine for malaria prophylaxis in nonimmune travelers: results from a randomized, double-blind study," Clinical Infectious Diseases, vol. 33, no. 7, pp. 10151021, 2001. 
[12] J. Keeven, S. Wrobel, M. Portoles, and B. T. DeCicco, "Evaluating the preservative effectiveness of RGP lens care solutions," CLAO Journal, vol. 21, no. 4, pp. 238-241, 1995.

[13] D. Kirpichnikov, S. I. McFarlane, and J. R. Sowers, "Metformin: an update," Annals of Internal Medicine, vol. 137, no. 1, pp. 25-33, 2002.

[14] W. R. Lee, K. M. Tobias, D. A. Bemis, and B. W. Rohrbach, "In vitro efficacy of a polyhexamethylene biguanide-impregnated gauze dressing against bacteria found in veterinary patients," Veterinary Surgery, vol. 33, no. 4, pp. 404-411, 2004.

[15] G. J. Motta, C. T. Milne, and L. Q. Corbett, "Impact of antimicrobial gauze on bacterial colonies in wounds that require packing," Ostomy/Wound Management, vol. 50, no. 8, pp. 48-62, 2004.

[16] M. Rosin, A. Welk, O. Bernhardt et al., "Effect of a polyhexamethylene biguanide mouthrinse on bacterial counts and plaque," Journal of Clinical Periodontology, vol. 28, no. 12, pp. 1121-1126, 2001.

[17] S. R. Passic, M. L. Ferguson, B. J. Catalone et al., "Structureactivity relationships of polybiguanides with activity against human immunodeficiency virus type 1," Biomedicine and Pharmacotherapy, vol. 64, no. 10, pp. 723-732, 2010.

[18] N. Thakkar, V. Pirrone, S. Passic et al., "Specific interactions between the viral coreceptor CXCR4 and the biguanide-based compound NB325 mediate inhibition of human immunodeficiency virus type 1 infection," Antimicrobial Agents and Chemotherapy, vol. 53, no. 2, pp. 631-638, 2009.

[19] N. Thakkar, V. Pirrone, S. Passic et al., "Persistent interactions between biguanide-based compound NB325 and CXCR4 result in prolonged inhibition of human immunodeficiency virus type 1 infection," Antimicrobial Agents and Chemotherapy, vol. 54, no. 5, pp. 1965-1972, 2010.

[20] B. J. Catalone, T. M. Kish-Catalone, L. R. Budgeon et al., "Mouse model of cervicovaginal toxicity and inflammation for preclinical evaluation of topical vaginal microbicides," Antimicrobial Agents and Chemotherapy, vol. 48, no. 5, pp. 1837-1847, 2004

[21] B. J. Catalone, T. M. Kish-Catalone, E. B. Neely et al., "Comparative safety evaluation of the candidate vaginal microbicide C31G," Antimicrobial Agents and Chemotherapy, vol. 49, no. 4, pp. 1509-1520, 2005.

[22] B. J. Catalone, M. L. Ferguson, S. R. Miller et al., "Prolonged exposure to the candidate microbicide C31G differentially reduces cellular sensitivity to agent re-exposure," Biomedicine and Pharmacotherapy, vol. 59, no. 8, pp. 460-468, 2005.

[23] B. J. Catalone, S. R. Miller, M. L. Ferguson et al., "Toxicity, inflammation, and anti-human immunodeficiency virus type 1 activity following exposure to chemical moieties of C31G," Biomedicine and Pharmacotherapy, vol. 59, no. 8, pp. 430-437, 2005.

[24] L. P. O’Malley, A. N. Collins, and G. F. White, "Biodegradability of end-groups of the biocide polyhexamethylene biguanide (PHMB) assessed using model compounds," Journal of Industrial Microbiology and Biotechnology, vol. 33, no. 8, pp. 677684, 2006.

[25] D. Tien, R. L. Schnaare, F. Kang et al., "In vitro and in vivo characterization of a potential universal placebo designed for use in vaginal microbicide clinical trials," AIDS Research and Human Retroviruses, vol. 21, no. 10, pp. 845-853, 2005.

[26] T. R. Moench, R. J. Mumper, T. E. Hoen, M. Sun, and R. A. Cone, "Microbicide excipients can greatly increase susceptibility to genital herpes transmission in the mouse," BMC Infectious Diseases, vol. 10, article 331, 2010.
[27] C. K. Mauck, D. H. Weiner, M. D. Creinin, K. T. Barnhart, M. M. Callahan, and R. Bax, "A randomized Phase I vaginal safety study of three concentrations of C31G vs. Extra Strength Gynol II," Contraception, vol. 70, no. 3, pp. 233-240, 2004.

[28] C. K. Mauck, R. G. Frezieres, T. L. Walsh, S. W. Schmitz, M. M. Callahan, and R. Bax, "Male tolerance study of 1\% C31G," Contraception, vol. 70, no. 3, pp. 221-225, 2004.

[29] C. K. Mauck, M. D. Creinin, K. T. Barnhart et al., "A Phase I comparative postcoital testing study of three concentrations of C31G," Contraception, vol. 70, no. 3, pp. 227-231, 2004.

[30] S. Patel, E. Hazrati, N. Cheshenko et al., "Seminal plasma reduces the effectiveness of topical polyanionic microbicides," Journal of Infectious Diseases, vol. 196, no. 9, pp. 1394-1402, 2007.

[31] A. R. Neurath, N. Strick, and Y. Y. Li, "Role of seminal plasma in the anti-HIV-1 activity of candidate microbicides," BMC Infectious Diseases, vol. 6, article 150, 2006.

[32] J. A. Martellini, A. L. Cole, N. Venkataraman et al., "Cationic polypeptides contribute to the anti-HIV-1 activity of human seminal plasma," FASEB Journal, vol. 23, no. 10, pp. 3609$3618,2009$. 

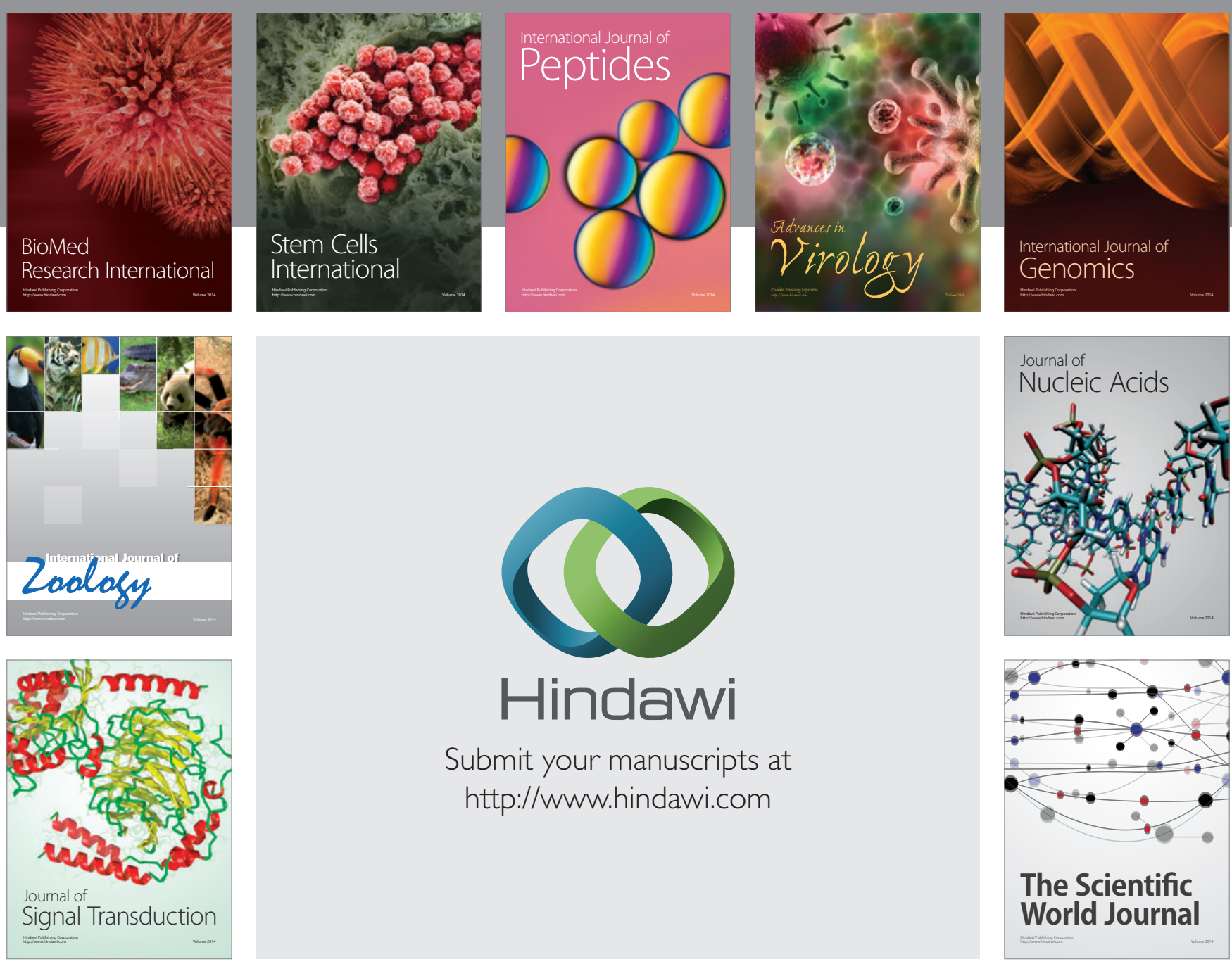

Submit your manuscripts at

http://www.hindawi.com
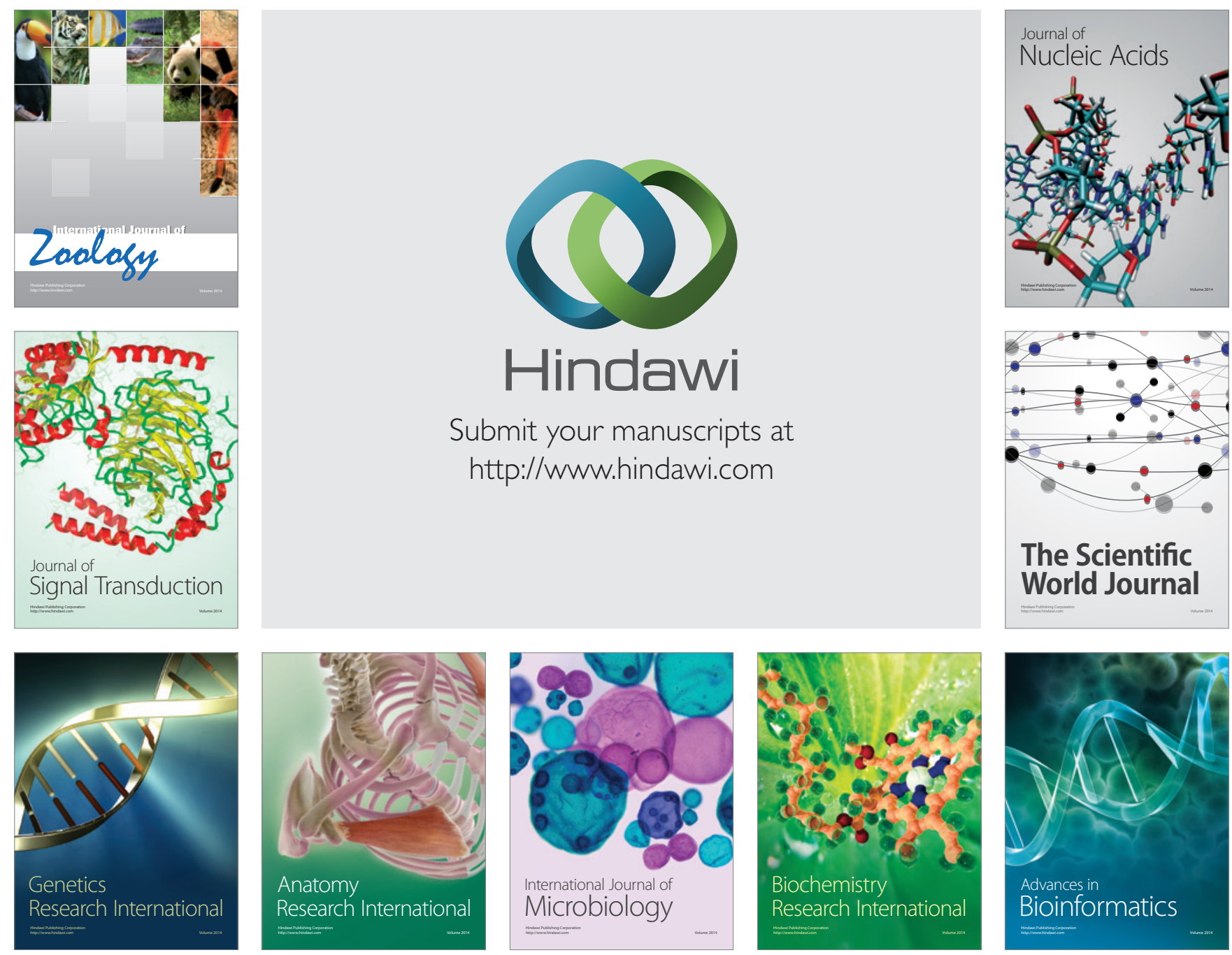

The Scientific World Journal
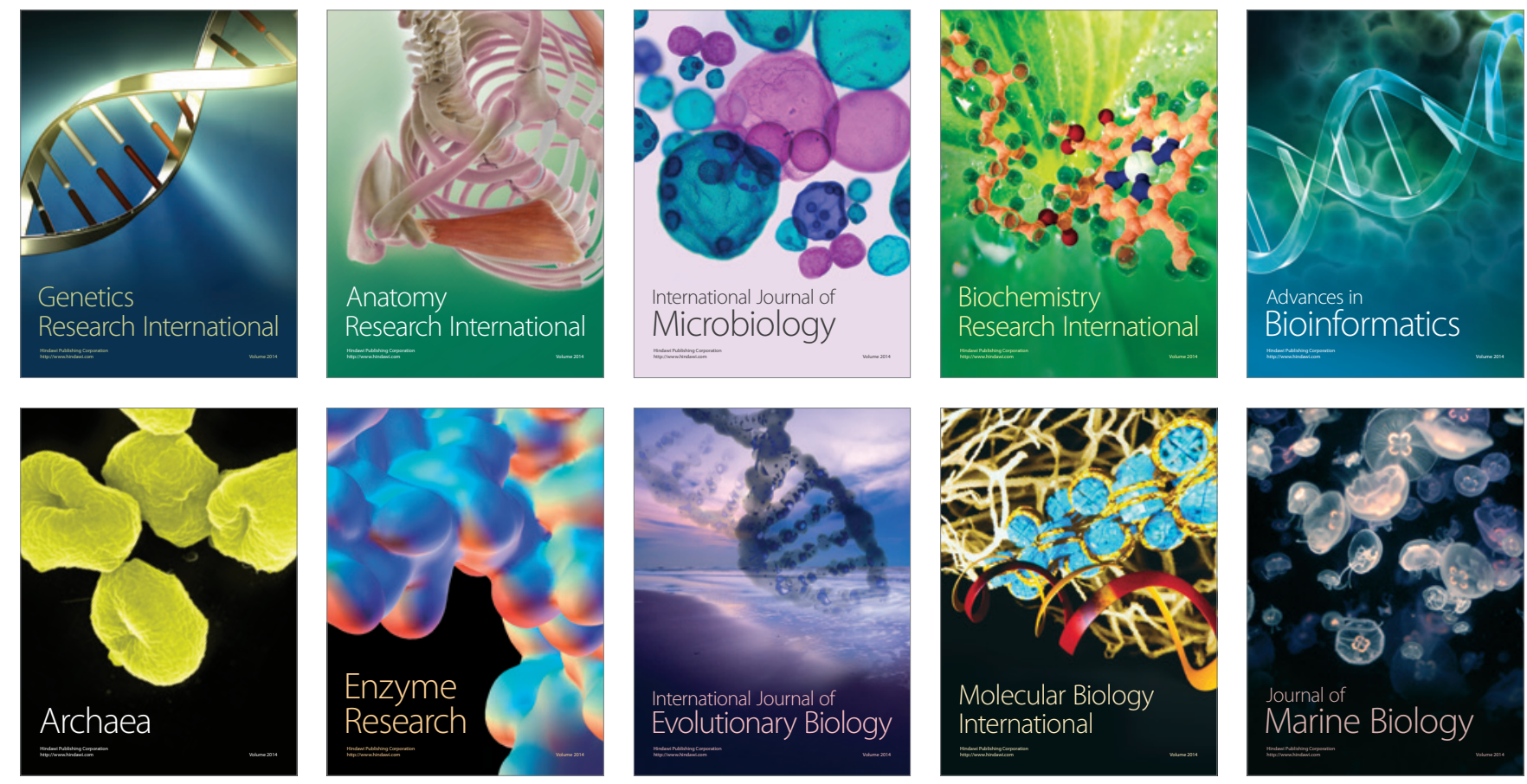